\title{
AVALIAÇÃO DA QUALIDADE DE SERVIÇOS TERCEIRIZADDOS DE INTERVENÇÃO EM MOBILIÁRIO E NO LAYOUT EM UMA ORGANIZAÇÃO PÚBLICA
}

\author{
QUALITY ASSESSMENT OF THE OUTSOURCING \\ SERVICES OF THE FURNITURE AND LAYOUT INTERVENTION \\ IN A PUBLIC ORGANIZATION
}

Data de submissão: 31-12-2012 Aceite: $11-02-2014$

Maria Aparecida Gouvêa ${ }^{1}$ Ricardo Lopes Pinto ${ }^{2}$ Braulio Oliveira ${ }^{3}$

\section{RESUMO}

Este estudo teve por objetivo identificar, no âmbito de uma organização pública, indicadores que possibilitem uma avaliação da qualidade do serviço terceirizado de manutenção de layout segundo as perspectivas dos usuários, dos fiscais de contratos e dos responsáveis pelos prestadores de serviços. Por meio da técnica estatística de modelagem de equações estruturais, obteve-se a definição dos constructos diretamente relevantes para a aferição da qualidade do serviço de manutenção de layout. Com base nos resultados de quatro pesquisas (uma quantitativa, realizada com usuários; e três qualitativas, sendo uma para cada segmento: usuários, fiscais e prestadores de serviços), foi possível comparar os rankings dos aspectos que conduzem à qualidade percebida dos serviços com base nos três segmentos de interesse neste trabalho. Os principais indicadores e suas avaliações poderão estar presentes na elaboração dos contratos entre fornecedores e contratante e atuar como referências no monitoramento da prestação de manutenção de layout no caso da empresa pesquisada.

Palavras-chave: Qualidade de serviços; Serviços terceirizados; Organização pública.

\footnotetext{
${ }^{1}$ Possui graduação em Bacharelado em Estatística e Bacharelado em Letras pela Universidade de São Paulo - USP, mestrado em Estatística pela Universidade de São Paulo - USP e doutorado em Administração pela Universidade de São Paulo - USP. Atualmente é professora no Departamento de Administração da FEA/USP. São Paulo. São Paulo. Brasil. E-mail: magouvea@usp.br

${ }^{2}$ Possui graduação em Engenharia de Produção Mecânica pela Universidade de São Paulo - USP, graduação em Ciências Contábeis pelo Instituto Educacional São Paulo - IESP, mestrado em Administração pela Universidade de São Paulo - USP e doutorado em Administração pela Universidade de São Paulo - USP. Atualmente é servidor público federal. São Paulo. São Paulo. Brasil. E-mail: ricardo.lopes@bcb.gov.br

${ }^{3}$ Possui graduação em Administração pela Universidade Presbiteriana Mackenzie - MACKENZIE, mestrado em Administração de Empresas pela Universidade Presbiteriana Mackenzie - MACKENZIE e doutorado em Administração pela Universidade de São Paulo - USP. São Paulo. São Paulo. Brasil. E-mail: braulio@usp.br
} 


\section{ABSTRACT}

This study aimed to identify, within the framework of a public organization, indicators allowing an assessment of the quality of outsourced service maintenance of layout according to the perspectives of users, of contract fiscals and of the responsible for service providers.

Through the statistical technique of structural equations modeling, the definition of constructs directly relevant to the measurement of quality of service of maintenance of layout has been obtained. On the basis of the results of four surveys (a quantitative one with service users and three qualitative, each of them with each segment: users, fiscals and service providers) it was possible to compare the rankings of the aspects that lead to perceived quality of the services in accordance with the three segments of interest in this work. The main indicators and their assessments may be considered by the company focused in this study as items in the drawing up of contracts between suppliers and contracting part and as references in monitoring the provision of maintenance of layout.

Keywords: Services quality; Outsourcing services; Public organization.

\section{INTRODUÇÃO}

A Reforma Administrativa de 1995, também conhecida como Reforma Gerencial, possibilitou aos governos o repasse de atividades até então desenvolvidas pelo Estado para organizações sociais, bem como estabeleceu o princípio de que a produção de bens e a prestação de serviços não exclusivos do Estado deveriam ser de atribuição de instituições privadas (PEREIRA, 2001). Isso implicou a orientação para a ampla terceirização de atividades de apoio, principalmente no que se refere a serviços de limpeza, segurança patrimonial, manutenção predial e transportes, passando então o Estado a ser comprador desses serviços no mercado.

Dado que tal orientação ampliou bastante, tanto em quantidade como em complexidade, o rol de itens adquiridos pelo Estado e o volume de dinheiro público gasto com compras e contratações, com o passar do tempo, a regulamentação para compras e contratações públicas foi sendo aprimorada, a fim de resguardar o interesse público e de desfavorecer a corrupção.

No Brasil, para a contratação de serviços pela Administração Pública, a escolha de um fornecedor deve necessariamente ser feita por meio de uma licitação (BRASIL, 1993). Isso significa que, via de regra, o critério de seleção da melhor oferta de serviço consiste no menor preço, desde que atendidas as exigências em termos de um patamar mínimo de qualidade e de desempenho estabelecido em edital de convocação (BRASIL, 1993; BRASIL, 2002).

Para garantir que os serviços contratados sejam prestados conforme o estabelecido, 0 artigo 67 da Lei n. 0 8666/93 determina que sua fiscalização fique sob a responsabilidade de um representante da Administração Pública formalmente designado (o fiscal do contrato), ao qual cabe o acompanhamento das atividades desenvolvidas pela contratada, bem como a incumbência de exigir o estrito cumprimento das obrigações assumidas pela empresa. É sua responsabilidade, também, solicitar providências a seus superiores naquilo que se referir ao serviço que fiscaliza. Caso a empresa contratada não cumpra qualquer das obrigações assumidas em função da contratação, está sujeita, após concluído processo administrativo para apuração de irregularidades, à rescisão do contrato e à aplicação de outras sanções administrativas (BRASIL, 1993).

Assim, a qualidade nos serviços prestados à Administração Pública deve ser um elemento levado em consideração e mantido sob o controle do contratante. Diante disso, neste trabaIho, o objetivo consistiu em abordar a questão da qualidade de serviços terceirizados no âmbito de uma organização pública autárquica. Trata-se de uma situação que envolve um consumidor multifacetado (neste estudo, a organização focalizada) e fornecedores multifacetados (empresas 
contratadas para a prestação de serviços), de modo que há relacionamentos entre vários funcionários de cada uma das organizações envolvidas no negócio.

Na organização pesquisada, a avaliação da qualidade tem sido subjetiva e informal, baseada na percepção do fiscal e de outros servidores responsáveis pelo acompanhamento dos serviços contratados, sem que sejam feitas pesquisas periódicas junto aos usuários para avaliação dos serviços prestados a eles ou pesquisas junto aos prestadores de serviços para coletar sua percepção sobre a qualidade dos serviços que fornecem. Assim, a rigor, não há como saber se os serviços terceirizados contratados são considerados de qualidade também pelos usuários e pelos prestadores dos serviços.

Um dos serviços que têm sido objeto de reclamação por parte dos funcionários da empresa contratante, por exemplo, refere-se a um pacote de serviços aqui denominado layout: reparos em móveis e alterações das posições do mobiliário e das divisórias. Tendo isso em vista, emerge a situação-problema que motivou a realização deste estudo: quais são os aspectos relevantes na avaliação da qualidade do serviço de layout e qual o grau de qualidade percebida na prestação deste serviço?

Este estudo tem, assim, o intuito de identificar, no âmbito de uma organização pública, indicadores que possibilitem uma avaliação da qualidade do serviço terceirizado de intervenção em mobiliário e no layout considerando as perspectivas dos usuários, dos fiscais de contratos e dos responsáveis pelos prestadores de serviços.

\section{FUNDAMENTAÇÃO TEÓRICA}

Esta seção apresenta o conceito de qualidade em serviços e alguns modelos teóricos que nortearam o desenvolvimento deste trabalho.

\subsection{Qualidade em serviços}

Apesar de os serviços serem considerados o centro das atividades econômicas do mundo moderno e estarem instaurados na sociedade desde os primórdios da vida social, os estudos acerca de qualidade em serviços e a instalação desta matéria na agenda dos administradores são recentes (início na década de 1980). "Na literatura de marketing de serviços uma abordagem à qualidade orientada para os serviços foi introduzida por Grönroos em 1982 com o conceito de Qualidade Percebida do Serviço e o Modelo de Qualidade Total do Serviço" (GRÖNROOS, 1993, p. 46).

Há várias formas de avaliar a qualidade, sendo a mais difundida a comparação entre a qualidade percebida e a qualidade esperada. Simié e Carapié (2008) destacam que muitos estudos foram realizados no campo de qualidade em serviços nas décadas de 80 e 90, dos quais resultaram modelos para avaliar esse quesito.

Em 1983, Zeithaml et al. iniciaram ampla pesquisa na área de qualidade em serviços, resultando: (i) na proposição de uma definição de qualidade em serviços; (ii) no entendimento da qualidade em serviços como um conceito multidimensional; (iii) no modelo de qualidade em serviços baseado em lacunas; e (iv) na escala SERVQUAL como instrumento de mensuração da qualidade em serviços.

Os trabalhos de Grönroos (1993) e Zeithaml et al. (1990) entendem que a qualidade percebida advém da relação entre expectativa e percepção dos consumidores, relação já pesquisada por Oliver (1980) em estudos sobre a satisfação do consumidor.

No início da década de 1990, Cronin Jr. e Taylor (1992) contestam muitas das proposições de Zeithaml et al. (1990) e propõem uma nova metodologia de avaliação de qualidade em serviço denominada SERVPERF, em que a qualidade é medida essencialmente pela percepção do consumidor. Dessa forma, Cronin Jr. e Taylor (1992) afirmam a não necessidade de quantificar as expectati- 
vas do consumidor, sendo este ponto a principal distinção entre as duas linhas de pesquisa.

Deve-se levar em conta, nesse contexto, que a intangibilidade, heterogeneidade e inseparabilidade do serviço tornam complicada a mensuração da qualidade, bem como o oferecimento de uma qualidade padrão do serviço. Isso significa que é difícil garantir que o serviço seja executado exatamente da mesma forma para todos os clientes (YOON; SUH, 2004).

Muitos estudos foram realizados com base nos métodos SERVQUAL e SERVPERF em várias áreas de serviços, mantendo-se vivas as duas correntes teóricas (MEHTA; DURVASULA, 1998; ANGUR et al., 1999; LASSAR et al., 2000; MATOS; VEIGA, 2000; REIS, 2001; CARVALHO; LEITE, 2001; GONÇALVES et al., 2002; SURESHCHANDAR et al., 2002; MELLO et al., 2002, CUI et al., 2003; MIGUEL; SALOMI, 2004; SALOMI et al., 2005).

\subsubsection{Escalas SERVQUAL e SERVPERF}

A escala SERVQUAL de Zeithaml et al. (1990) é fruto de uma portentosa pesquisa quantitativa operacionalizada a partir das conclusões obtidas na fase qualitativa de seus estudos. Esses autores desenvolveram a escala SERVQUAL com base em um modelo de qualidade de serviços elaborado por eles (Figura 1), no qual a percepção do cliente é a referência para a avaliação da qualidade do serviço prestado (PARASURAMAN et al, 1985, p. 44-46).

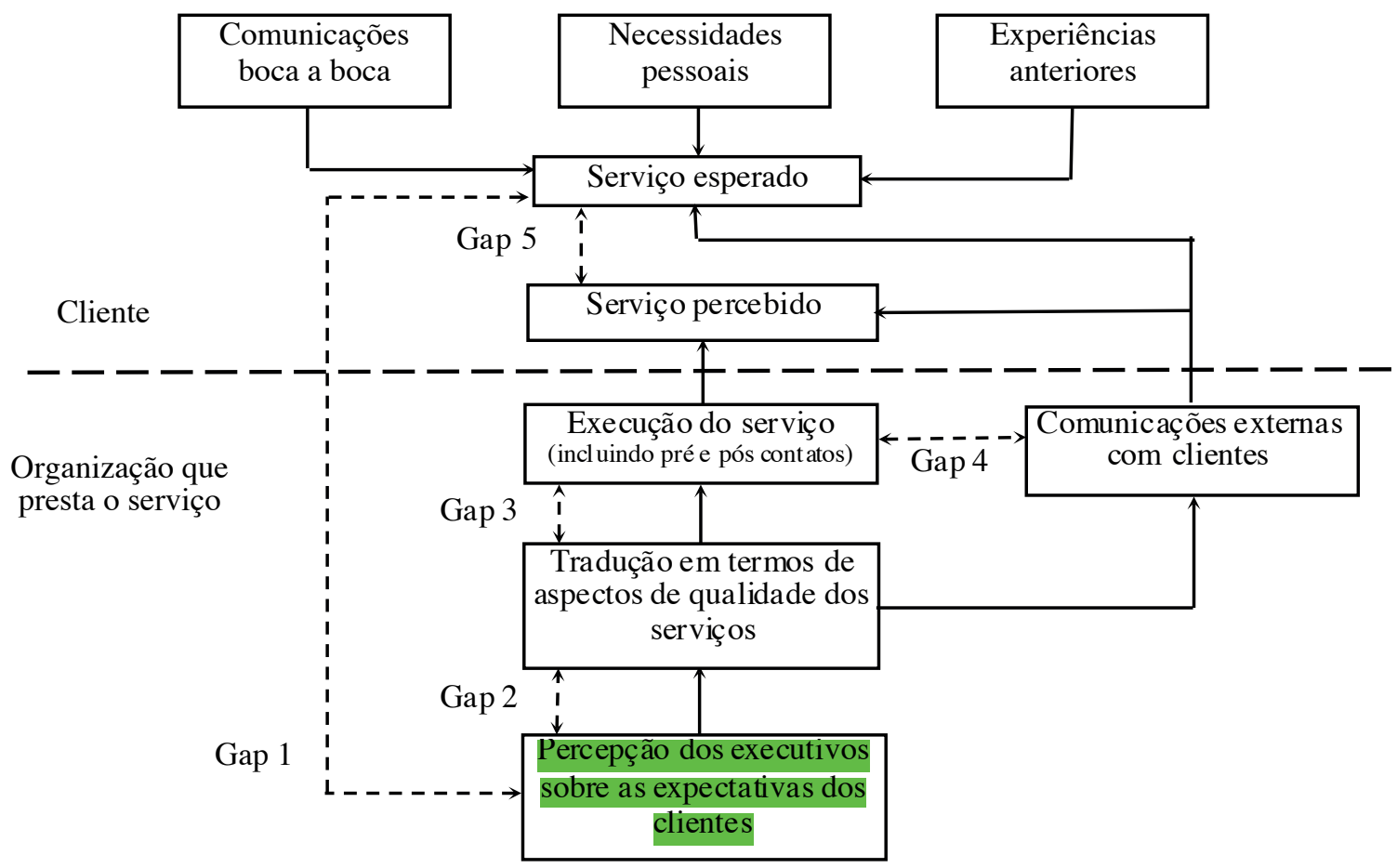

Figura 1 - Modelo de qualidade de serviços adotado na Escala SERVQUAL.

Fonte: Parasuraman et al. (1985, p. 44).

Nessa escala, a qualidade percebida do serviço (Gap 5) é a variável dependente, enquanto os outros quatro gaps são as variáveis independentes (SALOMI et al., 2005, p. 281). Cabe salientar que a variável dependente, qualidade percebida do serviço (Q), é função da diferença entre o desempenho do serviço $(P)$ e a expectativa $(E)$, conforme representado pela expressão $Q$ $=\mathrm{P}-\mathrm{E}$ (PARASURAMAN et al., 1988, p. 19). 
Na escala SERVQUAL, a mensuração ocorre mediante respostas a 44 itens ( 22 itens para captar a expectativa quanto a um serviço excelente e 22 itens para avaliar o serviço efetivamente prestado), com temática distribuída em cinco dimensões (confiabilidade, prontidão, segurança, empatia e tangibilidade): para cada item, o respondente deve escolher respostas que variam de "não essencial" a "absolutamente essencial" em escalas do tipo Likert com sete pontos (PARASURAMAN et al., 1988, p. 38-40). Estruturada sobre os eixos "expectativa" e "percepção", refletindo a definição de qualidade em serviços proposta por Zeithaml et al. (1990) e contemplando uma abordagem multidimensional, a escala SERVQUAL permite aferir e gerenciar uma medida de qualidade em serviços (escore SERVQUAL), bem como compreender suas principais lacunas (gaps) do ponto de vista do consumidor.

Apesar do prestígio atrelado à escala SERVQUAL, a metodologia utilizada encontra em Carman (1990), Teas (1993; 1994), Cronin Jr. e Taylor (1994) e Jain e Gupta (2004) alguns de seus críticos. O primeiro contesta as cinco dimensões da qualidade propostas por Zeithaml et al. (1990), e os demais propõem métricas alternativas para a aferição da qualidade.

Cronin Jr. e Taylor (1994), ao criticar a escala SERVQUAL, propõem a escala SERVPERF, postulando que a qualidade em serviços deve ser medida exclusivamente a partir da percepção de desempenho do serviço. Os atributos utilizados para a avaliação da qualidade em serviços são os mesmos na escala SERVQUAL e SERVPERF, porque os 22 itens representando as cinco dimensões da qualidade de serviço propostos por Parasuraman et al. (1988, p. 39-40) foram considerados bem-embasados teoricamente para a mensuração da percepção de desempenho do serviço prestado (CRONIN; TAYLOR, 1992, p. 58). Dessa forma, no que tange aos elementos-chave da avaliação dos serviços, Cronin Jr. e Taylor (1992) não apresentam nova conceituação, considerando adequada a relação de atributos proposta por Zeithaml et al. (1990).

As conclusões que levaram Cronin Jr. e Taylor (1992) à proposição da escala SERVPERF apoiam-se em uma pesquisa quantitativa operacionalizada em quatro atividades do setor de serviços (bancos, dedetizadoras, lavanderias e fastfoods) em uma cidade de médio porte dos Estados Unidos no início da década de 1990. Nesse estudo, comparou-se a sensibilidade em retratar as variações de qualidade de serviços da escala SERVQUAL completa com a de apenas uma parte dela (aquela relativa à avaliação da percepção de desempenho do serviço prestado). 0 pressuposto empregado é de que a qualidade percebida do serviço $(Q)$ é conceituada como uma atitude do cliente, de modo que pode ser apurada mediante uma avaliação do desempenho do serviço (P), consoante a expressão $Q=P$ (SALOMI et al., 2005, p. 283).

Por meio de uma análise baseada na modelagem de equações estruturais, Cronin Jr. e Taylor (1992) apontam a não confirmação das cinco dimensões SERVQUAL, propondo a operacionalização unidimensional dos atributos componentes da escala. Alguns outros estudos comparando os resultados obtidos por escalas SERVQUAL e SERVPERF chegaram à conclusão de que esta é suficientemente robusta para a mensuração da qualidade percebida do serviço (JAIN; GUPTA, 2004; SALOMI et al., 2005; BAYRAKTAROGLU, 2010).

A escala SERVPERF é frequentemente citada pela facilidade de sua operacionalização, bem como pelos melhores índices de confiabilidade quando comparados à escala SERVQUAL (CRONIN JR.; TAYLOR, 1992; CRONIN JR.; TAYLOR, 1994; LEE et al., 2000). No entanto, alguns estudos contradizem esse entendimento (ANGUR et al., 1999) e complementam afirmando que a metodologia tem, em sua concepção, um menor grau de compreensão do consumidor, por não abordar seus desejos e suas expectativas (PARASURAMAN et al., 1994; ANGUR et al., 1999). 


\subsubsection{Modelo hierárquico de qualidade de serviços de Brady e Cronin Jr. (2001)}

Um modelo alternativo de mensuração da qualidade de serviços foi proposto por Brady e Cronin Jr. (2001). Esses autores elaboraram um modelo de qualidade de serviços que tem o mérito de decompor a qualidade percebida de um serviço em vários níveis hierárquicos, permitindo uma compreensão mais profunda dos mecanismos que conduzem à qualidade do serviço.

Brady e Cronin Jr. (2001) elaboraram um modelo de qualidade de serviços que incorpora as ideias de Rust e Oliver (1994) (quanto à qualidade de serviço como composição dos constructos ambiente do serviço, entrega do serviço e resultado do serviço) e de Dabholkar, Thorpe e Rentz (1996) (sobre um modelo de qualidade em que os constructos se dispõem em níveis). Nesse modelo, a qualidade do serviço é entendida como constructo influenciado por três constructos de segunda ordem (qualidade de interação, qualidade do ambiente físico e qualidade do resultado), cada um deles também influenciado por três constructos de primeira ordem, compostos de indicadores de três tipos: confiabilidade, prontidão e empatia (Figura 2).

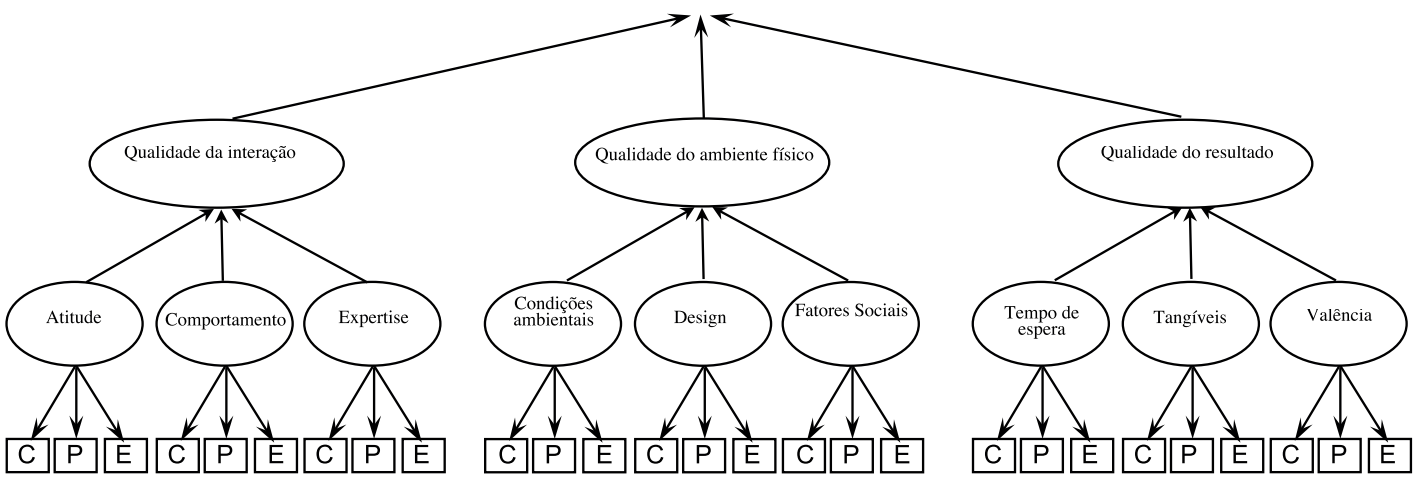

Nota: $\mathrm{C}$ = indicador de confiabilidade; $\mathrm{P}$ = indicador de prontidão e $\mathrm{E}=$ indicador de empatia.

Figura 2 - Modelo hierárquico de qualidade de serviços

Fonte: Brady; Cronin Jr. (2001, p. 37).

Em uma fase inicial, Brady e Cronin Jr. (2001) realizaram um estudo qualitativo e quantitativo, direcionado para oito serviços distintos, com o intuito de identificarem as subdimensões e os itens que os consumidores associavam às componentes de ordem superior: qualidade da interação, qualidade do ambiente físico e qualidade do resultado. Aos entrevistados foi solicitado que listassem todas as variáveis que influenciavam as suas percepções em cada uma das três componentes referidas, as quais foram alvo de categorização e posterior refinamento. Determinaram, assim, nove subdimensões, agregadas em grupos de três e distribuídas pelas três componentes de ordem superior do seguinte modo: as subdimensões atitude, comportamento e expertise foram ligadas à qualidade da interação; as subdimensões condições ambientais, design e fatores sociais foram associadas à qualidade do ambiente físico; e as subdimensões tempo de espera, elementos tangíveis e resultado da experiência (valência) foram associadas à qualidade do resultado.

Já o estudo quantitativo desenvolvido para os oito serviços abarcou 35 itens, quatro indústrias e 1133 entrevistas. A aplicação do modelo aos oito serviços permitiu corroborar as relações entre os constructos e os indicadores incluídos em cada um deles. Com base na aplicação da técnica estatística modelagem de equações estruturais, os autores chegaram às seguintes conclusões:

- atitudes, comportamento e expertise afetam a qualidade da interação;

- a qualidade da interação afeta a percepção da qualidade do serviço; 
- condições ambientais, design e fatores sociais afetam a percepção da qualidade do ambiente físico;

- a percepção da qualidade do ambiente físico afeta a percepção da qualidade do serviço;

- tempo de espera, tangíveis e valência afetam a percepção da qualidade do resultado;

- a percepção da qualidade do resultado afeta a percepção da qualidade do serviço;

- empatia, prontidão e confiabilidade são relevantes para o fornecimento de serviços de alta qualidade.

Esse estudo teve desdobramentos ao ser desenvolvido por outros autores. Caro e García (2008), Lu et al. (2009) e Chahal e Kumari (2010) executaram estudos propondo modelos de mensuração de qualidade de serviços inspirados no modelo de Brady e Cronin Jr. (2001). Também outros autores adotaram o modelo de Brady e Cronin Jr. (2001) para a realização de suas pesquisas, seja porque esse modelo comprovou com dados empíricos a hierarquização dos fatores e das dimensões do constructo de qualidade em serviço - o que vinha sendo mencionado em outros trabalhos teóricos (FASSNACHT; COESE, 2006), seja porque propõe uma abordagem unificada que concebe a qualidade de serviço pela integração de diferentes dimensões (VÖLCKNER et al., 2010).

Ademais, pesquisa recente realizada por Mittal, Gera e Singhvi (2013) no setor de seguros na Índia permite concluir que o modelo de Brady e Cronin Jr. (2001) ainda se mostra adequado, uma vez que tal pesquisa obteve resultado semelhante quanto à estrutura da qualidade de serviços.

Os modelos apresentados nesta fundamentação teórica consistiram nas principais diretrizes que nortearam a realização desta pesquisa em uma organização pública.

\section{ASPECTOS METODOLÓGICOS}

Neste trabalho, o estudo de caso foi escolhido como modo de investigação. Segundo Yin (2005, p. 32), um estudo de caso é "uma investigação empírica que analisa um fenômeno contemporâneo dentro de seu contexto real, quando os limites entre o fenômeno e o contexto não estão claramente definidos" e quando o pesquisador não possui controle sobre os eventos comportamentais, de forma que a coleta e análise de dados apresentam características específicas.

O problema em questão envolve um fenômeno contemporâneo (a avaliação informal da qualidade de serviços terceirizados prestados a uma autarquia pública ocorre corriqueiramente, decorrente da experiência com a prestação desses serviços) extremamente relacionado a um contexto (condições particulares da organização em relação à dinâmica do trabalho, à infraestrutura e às necessidades das pessoas), sinalizando ser pertinente a escolha da organização a ser estudada.

A seleção do caso para o estudo ocorreu de acordo com o Critério da Apropriabilidade dos Dados (MORSE, 1994). De fato, a escolha do caso foi intencional, procedimento justificável desde que o caso escolhido possua características tais que permitam o estudo adequado do problema de pesquisa. Os fatores considerados suficientes para caracterizar a apropriabilidade dos dados foram os seguintes:

- adequação ao problema de pesquisa (a instituição vivencia o desafio de encontrar formas de aferir a qualidade dos serviços terceirizados contratados);

- facilidade de acesso aos dados (um dos pesquisadores é servidor público da instituição e atualmente desempenha a função de fiscal de contratos de manutenção; portanto, tem fácil acesso a outros fiscais de contratos, aos usuários e aos prestadores de serviços, já que lida com eles em seu trabalho cotidiano);

- disposição da instituição para colaborar. 
Três perfis de respondentes foram estudados: usuários, fiscais de contratos e responsáveis pelos prestadores de serviços.

Foi adotada a recomendação de Yin (2005) de se empregar múltiplas fontes de dados e de informações, tendo sido realizadas pesquisa qualitativa para os três segmentos (com base em focus groups e em entrevistas em profundidade) e quantitativa junto aos usuários (mediante aplicação dos questionários estruturados). O objetivo principal das pesquisas qualitativas foi definir os indicadores para avaliação dos serviços terceirizados de layout que seriam posteriormente investigados por meio da aplicação de questionários. A coleta de dados das pesquisas qualitativa e quantitativa ocorreu em dezembro de 2009 e março de 2010, respectivamente.

A pesquisa qualitativa contou com dez usuários, cinco fiscais e cinco prestadores de serviços entrevistados. Ressalta-se que houve duas formas de abordagem em cada um dos três segmentos: focus group para a identificação de características de um serviço inaceitável de layout e as de um serviço de excelência; entrevistas individuais semiestruturadas para a revisão das listas de indicadores (características) obtidos. As entrevistas foram gravadas com consentimento dos respondentes. Foram feitas, também, anotações durante algumas entrevistas. A seleção dos respondentes foi intencional, com base na potencial contribuição que poderiam fornecer em função da interação de seu trabalho com as consequências em termos de qualidade do trabalho do pacote de serviços denominado layout.

Quanto à amostragem para a pesquisa quantitativa, esta ocorreu somente para os usuários; para os fiscais de contratos e responsáveis pelos prestadores de serviços, foram feitos censos, pois nenhum deles possuía mais de 50 elementos: apenas seis e dois, respectivamente. Dos 260 questionários enviados para os usuários, 203 foram recolhidos, sendo 176 considerados úteis, após eliminação de missings e outliers. Todos os questionários enviados para os demais perfis de respondentes foram devolvidos e apresentaram condições de pleno aproveitamento.

O tamanho de amostra dos usuários foi suficiente para produzir bons resultados no que se refere ao tratamento quantitativo aplicado (técnica de modelagem de equações estruturais com método de estimação baseado em componentes conhecido como PLS - Partial Least Squares), uma vez que foi adotada a recomendação de Marcolides et al. (2009) de calcular o tamanho mínimo da amostra com base na análise do poder do teste estatístico - cabe ressaltar que os autores inclusive criticam o uso da Rule of Thumb dos dez casos por indicador. A análise preliminar do poder (probabilidade de se rejeitar HO sendo ela falsa), empregando-se o software G*Power versão 3.0.10 (BUCHNER et al., 2008), revelou que o tamanho mínimo de amostra seria de 77 respondentes. Consequentemente, como a amostra empregada (176 questionários) é bastante superior ao tamanho mínimo (77 questionários), foi garantida sensibilidade suficiente para detectar como não relevante qualquer aspecto de qualidade realmente insignificante.

\subsection{Modelo de qualidade de serviços terceirizados de layout}

O modelo desenvolvido fundamenta-se em uma adaptação do Modelo Hierárquico de Qualidade de Serviços criado por Brady e Cronin Jr. (2001, p. 37), complementada pela definição de indicadores no contexto de manutenção de serviços de layout. A adaptação consistiu na exclusão de dois constructos: qualidade do ambiente físico e valência. Optou-se por não incluir qualidade do ambiente físico devido ao reduzido controle dos prestadores de serviços acerca da definição dos aspectos ligados a esse constructo. De fato, os prestadores de serviços devem fazer a manutenção em instalações cujas decisões sobre sua constituição cabem ao cliente, de modo que, nesse tipo de serviço, esse constructo está fora de seu controle e, em tese, não influenciaria 
a avaliação de diferentes prestadores de serviços. Já o constructo valência, que cobre todos os aspectos do resultado do serviço que não se referem nem ao tempo de espera nem aos aspectos tangíveis, deixou de ser incluído devido à impossibilidade de ser utilizado para fins de melhoria da gestão do serviço, já que os aspectos compreendidos na valência não são controláveis pelos gestores dos serviços, conforme enfatizam Brady e Cronin Jr. (2001).

A Figura 3, exposta a seguir, apresenta o modelo adaptado.

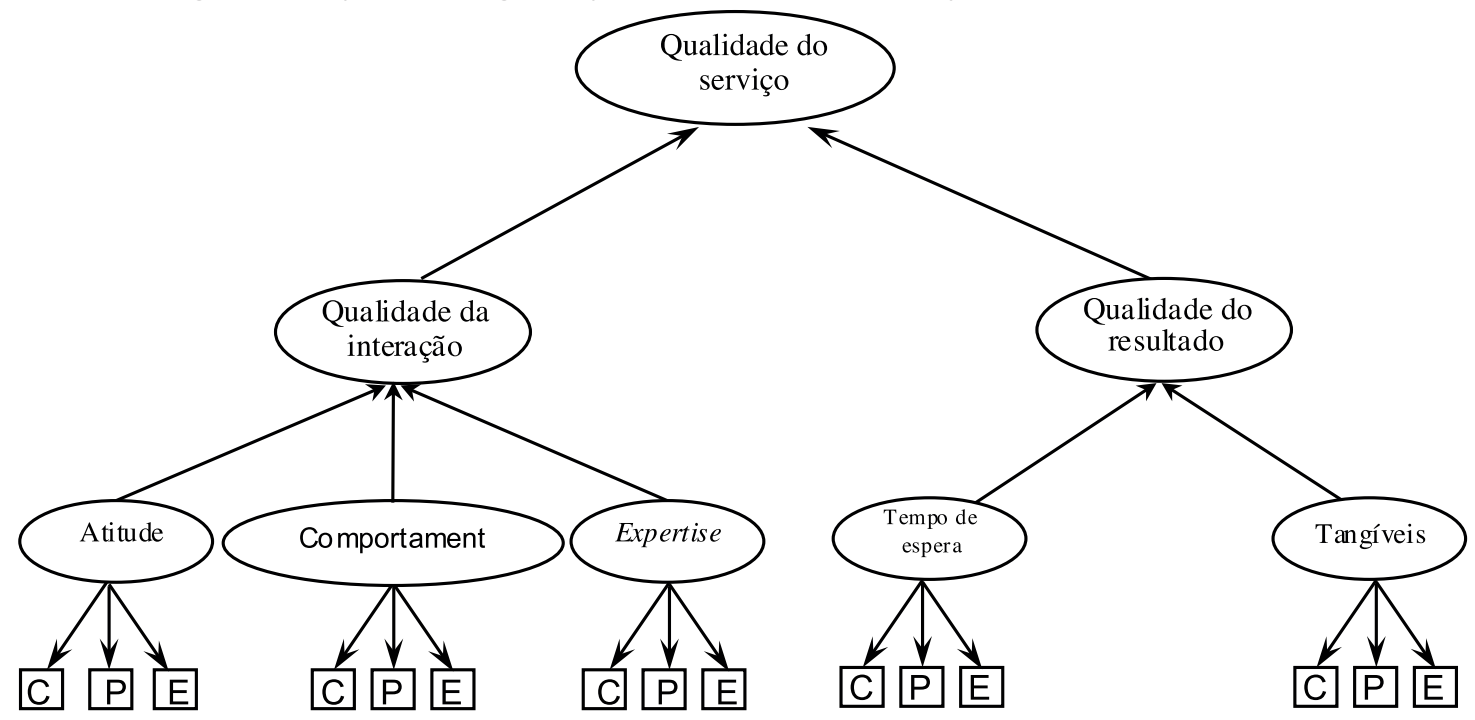

Nota: $\mathrm{C}=$ indicador de confiabilidade; $\mathrm{P}=$ indicador de prontidão e $\mathrm{E}=$ indicador de empatia.

Figura 3 - Modelo de qualidade de serviços terceirizados de layout

Fonte: Representação figurativa proposta pelos autores.

Os Quadros 1, 2 e 3, a seguir, apresentam todos os constructos com seus respectivos indicadores.

Quadro 1 - Indicadores dos constructos aspectos tangíveis e tempo de espera

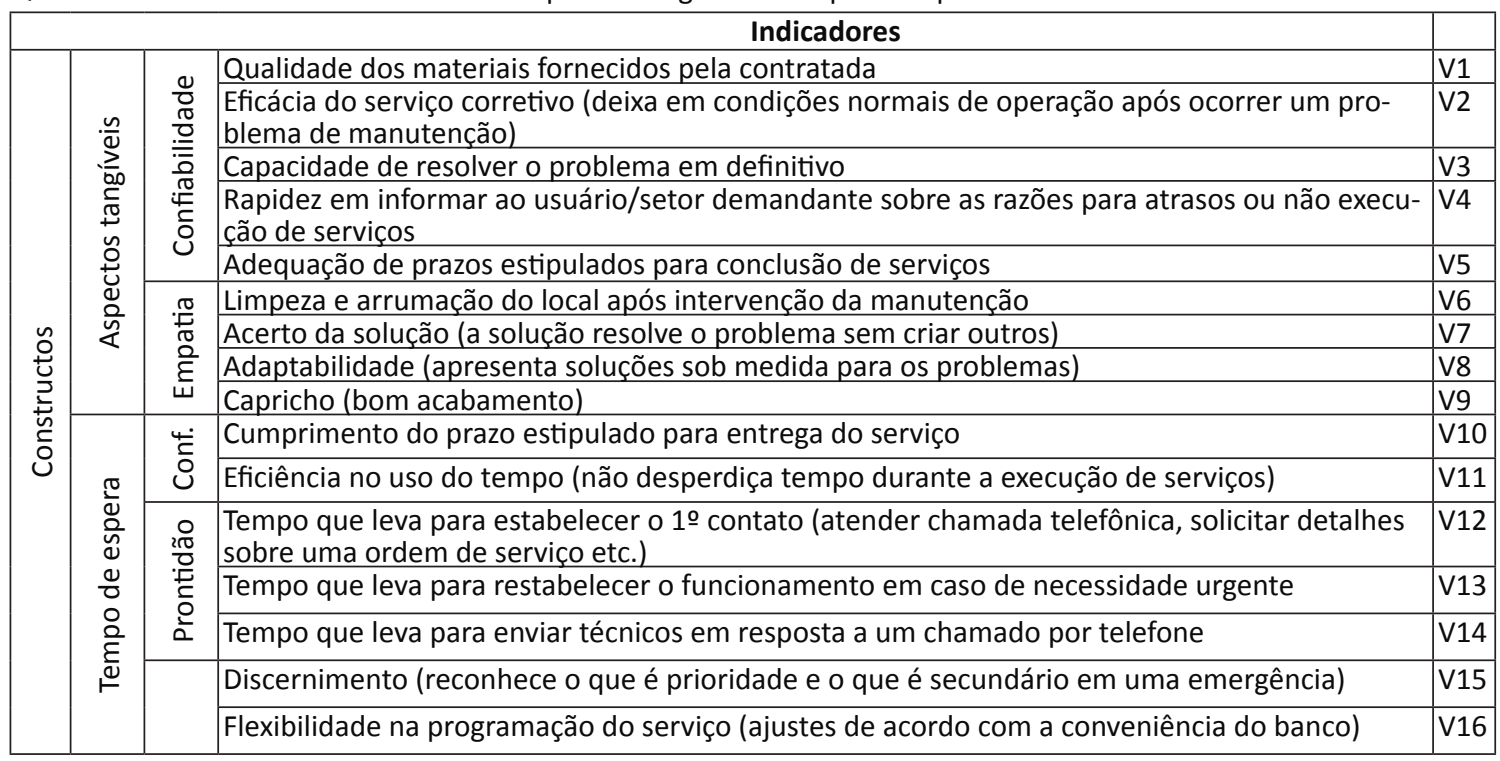

Fonte: elaborado pelos autores. 
Quadro 2 - Indicadores dos constructos atitude e comportamento

\begin{tabular}{|c|c|c|c|c|}
\hline & & & Indicadores & \\
\hline \multirow{19}{*}{ 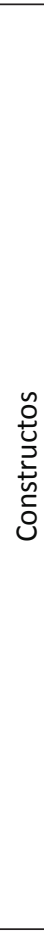 } & \multirow{9}{*}{ 尊 } & \multirow{2}{*}{$\begin{array}{l}\frac{0}{0} \\
\frac{\pi}{0} \\
\frac{0}{\overline{0}} \\
\frac{0}{\pi} \\
0 \\
0 \\
0\end{array}$} & Dedicação na execução do serviço & V17 \\
\hline & & & Relato exato de fatos (informações sobre os problemas e o andamento do serviço) & V18 \\
\hline & & \multirow{3}{*}{$\begin{array}{l}\frac{0}{2 \pi} \\
\frac{20}{0} \\
\frac{0}{c} \\
\frac{0}{0}\end{array}$} & Receptividade (assume a tarefa sem empurrar para outra pessoa) & V19 \\
\hline & & & $\begin{array}{l}\text { Proatividade (a manutenção começa a resolver o problema assim que ele surge, sem espe- } \\
\text { rar que o usuário peça) }\end{array}$ & V20 \\
\hline & & & $\begin{array}{l}\text { Conhecimento sobre o histórico de problemas (evita que o usuário tenha de explicar tudo } \\
\text { novamente a cada atendimento) }\end{array}$ & V21 \\
\hline & & \multirow{4}{*}{$\begin{array}{l}\stackrel{0}{\stackrel{0}{\pi}} \\
\stackrel{0}{0} \\
\stackrel{\sim}{E}\end{array}$} & Boa vontade de realizar serviços para evitar problemas futuros & V22 \\
\hline & & & Disposição em fornecer explicações sobre problemas identificados & V23 \\
\hline & & & Dá informações com antecedência sobre o que vai acontecer em termos de manutenção & V24 \\
\hline & & & Disposição de realizar reparos ao invés de substituir tudo & V25 \\
\hline & \multirow{10}{*}{ 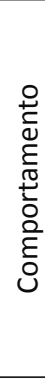 } & \multirow{3}{*}{$\begin{array}{l}\frac{1}{0} \\
\frac{10}{\pi} \\
\frac{10}{0} \\
c \\
0 \\
0\end{array}$} & Execução de tarefas conforme programação (faz sem necessidade de cobrança) & V26 \\
\hline & & & Fidedignidade (faz o que promete fazer) & $\mathrm{V} 27$ \\
\hline & & & Autoconfiança (está seguro do que faz) & V28 \\
\hline & & \multirow{3}{*}{ 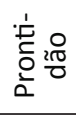 } & Disponibilidade em atender o banco fora do horário de expediente & V29 \\
\hline & & & Eficácia na coleta de informações sobre o problema antes de começar o serviço & V30 \\
\hline & & & Cooperação (auxilia o banco ao invés de procurar razões para não fazer o serviço) & V31 \\
\hline & & \multirow{4}{*}{ 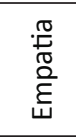 } & Disposição em considerar interesses e pontos de vista do banco & V32 \\
\hline & & & Apresentação pessoal (higiene e aparência) & V33 \\
\hline & & & Respeito aos limites de atuação (não invade o papel de outros agentes) & V34 \\
\hline & & & Paciência no trato com as pessoas & V35 \\
\hline
\end{tabular}

Fonte: elaborado pelos autores.

Quadro 3 - Indicadores dos constructos expertise, qualidade de interação, qualidade do resultado e qualidade do serviço

\begin{tabular}{|c|c|c|c|}
\hline & & Indicadores & \\
\hline & $\frac{1}{0}$ & Supervisão do trabalho (detecção e correção de problemas antes da entrega do serviço) & V36 \\
\hline & 党 & Capacidade técnica (capacidade de resolver problemas técnicos) & V37 \\
\hline & 容 & Controle de qualidade (atendimento com um nível de qualidade pelo menos aceitável) & V38 \\
\hline & 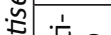 & Rapidez na detecç̃o de causas dos problemas & V39 \\
\hline & ¿ $\frac{2 \pi}{0}$ & Uso de recursos em quantidade suficiente (pessoas, ferramentas e materiais) & V40 \\
\hline & 离 & Capacidade de lidar com imprevistos & V41 \\
\hline & & Zelo na manipulação de materiais e bens do banco & V42 \\
\hline & है. & Zelo pela segurança das pessoas e dos bens no setor demandante & V43 \\
\hline 约 & 岀 & Capacidade de fazer o serviço sem incomodar & V44 \\
\hline 艺 & & Atendimento (cortesia, atenção etc.) feito pelas pessoas da manutenção em relação à sua expectativa & V45 \\
\hline 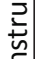 & 兽 & $\begin{array}{l}\text { Atendimento feito pelo pessoal da manutenção em comparação com a experiência que você já teve } \\
\text { com esse servico fora do banco }\end{array}$ & V46 \\
\hline 3. & $\frac{0}{0}$ & $\begin{array}{l}\text { Atendimento feito pelo pessoal da manutenção em comparação com o que seria o apropriado para } \\
\text { o banco }\end{array}$ & V47 \\
\hline & & Resolução de problemas de manutenção & V48 \\
\hline & 氖 & Resultados em comparação com a experiência que você já teve com esse tipo de serviço fora do banco & V49 \\
\hline & $\frac{0}{2} \div$ & Resultados em relação à sua expectativa & V50 \\
\hline & & Satisfação das necessidades por meio desse serviço (levando em conta todos os aspectos do serviço) & V51 \\
\hline & & Excelência na prestação do serviço em termos ge & V52 \\
\hline & 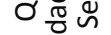 & Cobertura das expectativas com esse serviço em termos gerais & V53 \\
\hline
\end{tabular}

Todos os indicadores dos Quadros 1, 2 e 3 foram extraídos de pesquisas qualitativas junto a cada um dos três tipos de respondentes. Para a obtenção dos indicadores, foram seguidas as recomendações de Igea et al. (apud CALADO; FERREIRA, 2005): combinar três métodos de coleta de dados (observação do pesquisador, análise documental e entrevistas). A estratégia empregada foi a de definir indiretamente os indicadores: ao invés de colocar para os participantes das 
entrevistas a difícil tarefa de indicar quais seriam os indicadores relevantes para a avaliação dos serviços terceirizados de layout, preferiu-se coletar as informações que permitissem ao pesquisador inferir quais seriam esses indicadores.

Para tanto, os participantes dos focus groups foram estimulados a anunciarem quais eram as características que, em sua opinião, tipificavam um serviço inaceitável de layout; após a saturação de respostas a essa indagação, esses mesmos participantes foram encorajados a explicitarem quais eram as características que, em sua opinião, tipificavam um serviço de excelência em layout. Como foram feitos focus groups em separado com usuários, fiscais de contratos e responsáveis pelos prestadores de serviços, captou-se a perspectiva de cada uma dessas categorias de envolvidos com os serviços de layout.

A partir da documentação gerada nas entrevistas, procedeu-se à análise documental em três etapas: técnica de análise de conteúdo, consoante as orientações de Laville e Dione (1999); consolidação de dados em um único documento; e a análise de conteúdo com um modelo misto para definição de categorias analíticas. Os conhecimentos obtidos durante um período de seis meses de observação participante foram fundamentais para a categorização realizada.

Definidos os indicadores, foram feitas mais três pesquisas qualitativas exploratórias para a revisão da versão final das listas de indicadores por alguns dos respondentes das entrevistas em focus groups. Essas pesquisas consistiram em entrevistas individuais, abertas e semiestruturadas. A amostragem foi intencional, procedimento que reforça a validade de constructo do estudo.

Após a obtenção dos indicadores, verificou-se, com base na literatura pesquisada, que estes se classificavam em categorias (constructos). Ressalta-se que, além disso, foi feito um pré-teste com o questionário aplicado aos usuários a fim de verificar a adequação do instrumento de coleta de dados.

$\mathrm{Na}$ coleta de dados, solicitou-se que o respondente atribuísse a cada variável uma nota entre zero e dez, contextualizada em termos de uma escala de quatro conceitos: péssimo $(0 \mathrm{a}$ $2,4)$, ruim $(2,5$ a 4,9$)$, bom $(5,0$ a 7,4$)$ e ótimo $(7,5$ a 10). O Quadro 4 , exposto a seguir, apresenta as hipóteses testadas pelo modelo.

Quadro 4 - Resumo das hipóteses

\begin{tabular}{|c|l|}
\hline \multicolumn{2}{|c|}{ Hipótese } \\
\hline $\mathrm{H}_{1}$ & $\begin{array}{l}\text { A percepção sobre a qualidade de interação contribui diretamente para a percepção da qualidade } \\
\text { do serviço. }\end{array}$ \\
\hline $\mathrm{H}_{2}$ & $\begin{array}{l}\text { A percepção sobre as atitudes dos funcionários das empresas terceirizadas influencia diretamente } \\
\text { a percepção da qualidade de interação. }\end{array}$ \\
\hline $\mathrm{H}_{3}$ & $\begin{array}{l}\text { A percepção sobre o comportamento dos funcionários das empresas terceirizadas influencia dire- } \\
\text { tamente a percepção da qualidade de interação. }\end{array}$ \\
\hline $\mathrm{H}_{4}$ & $\begin{array}{l}\text { A percepção sobre a expertise dos funcionários das empresas terceirizadas influencia diretamente } \\
\text { a percepção da qualidade de interação. }\end{array}$ \\
\hline $\mathrm{H}_{5}$ & $\begin{array}{l}\text { A percepção sobre a qualidade do resultado contribui diretamente para a percepção da qualidade } \\
\text { do serviço. }\end{array}$ \\
\hline $\mathrm{H}_{6}$ & $\begin{array}{l}\text { A percepção sobre o tempo de espera influencia diretamente a percepção da qualidade do resul- } \\
\text { tado. }\end{array}$ \\
\hline $\mathrm{H}_{7}$ & $\begin{array}{l}\text { A percepção sobre os aspectos tangíveis do serviço influencia diretamente a percepção da quali- } \\
\text { dade do resultado. }\end{array}$ \\
\hline
\end{tabular}

Fonte: elaborado pelos autores.

Para testar o modelo apresentado na Figura 3, aplicou-se a técnica de modelagem de equações estruturais (MEE ou Structural Equation Modeling - SEM), por meio do software SmartPLS. Ressalta-se que o uso de modelagem por equações estruturais combinado a métodos qualitativos é considerado adequado por Jensen et al. (2010, p. 11) para determinar especificamente o valor percebido da gestão dos serviços de layout, já que possibilita a criação de escalas apropriadas. 


\section{RESULTADOS}

Nesta seção, são apresentados os seguintes tópicos: perfil da amostra, modelo de mensuração, modelo estrutural, comparação entre as três categorias de respondentes e avaliação dos indicadores.

A amostra é predominantemente masculina, com idade entre 50 e 60 anos, com grau de instrução elevado em relação ao verificado para a população brasileira (praticamente toda a amostra é composta de pessoas que cursaram pelo menos o ensino superior), com predomínio de ocupantes do cargo de analista e desempenhando funções em alguma das áreas consideradas atividades-fim da instituição.

A distribuição das variáveis sexo, idade, escolaridade e cargo traduziu com boa aproximação a situação do perfil de respondente referente aos usuários de serviços de layout, que são os funcionários da organização pesquisada.

\subsection{Modelo de mensuração}

A etapa de avaliação do modelo de mensuração consiste na verificação da adequação dos conceitos inseridos em cada um dos oito constructos do modelo apresentados nos Quadros 1,2 e 3.

Hair Jr. et al. (2005:126) recomendam a análise das validades convergente e discriminante:

- validade convergente - avalia o grau em que duas medidas do mesmo conceito estão correlacionadas;

- validade discriminante - consiste no grau em que dois conceitos são distintos.

A estatística Average Variance Extracted (AVE) permite medir o grau de validade:

- convergente - existente caso os valores da variância média extraída (Average Variance Extracted, AVE) dos constructos, que representa a sua relação com seus indicadores, sejam iguais ou superiores a 0,5 (ZWICKER et al., 2008). Cargas altas (0,7 ou superiores) das variáveis em seus respectivos constructos também indicam validade convergente (BIDO et al., 2008);

- discriminante - avaliada pela comparação das correlações entre os constructos com o valor da raiz quadrada da AVE daquele constructo e/ou pelo exame das cargas cruzadas entre os constructos e suas variáveis componentes (ZWICKER et al., 2008).

Conforme essas regras, houve necessidade de remoção das variáveis V20, V26 e V50. Os demais indicadores apresentaram cargas superiores a 0,7. Assim, houve pertinência na definição dos indicadores para cada um dos oito constructos do modelo deste estudo.

\subsection{Modelo estrutural}

A avaliação do modelo estrutural corresponde à análise da relação entre os constructos, permitindo testar as hipóteses exibidas no Quadro 4. Primeiramente, avaliaram-se os coeficientes estruturais referentes às relações entre pares de constructos. Após a obtenção do modelo final, com a manutenção de todos os coeficientes estruturais significantes, passou-se à análise das medidas gerais de qualidade de ajuste do modelo. 
Algumas medidas de qualidade do modelo utilizadas neste estudo, segundo definições de Zwicker et al. (2008), são:

- $\quad \mathbf{R}^{2}$ - variância explicada, grau em que as variáveis dependentes são previstas pelas independentes;

- Goodness-of-fit (GoF) - índice de adequação que mede quanto da variância é explicada pelo modelo, proposto por Tenenhaus et al. (2005 apud ZWICKER et al., 2008) e calculado pela média geométrica entre o $R^{2}$ médio (adequação do modelo estrutural) e a AVE média (adequação do modelo de mensuração).

A primeira etapa de análise revelou que o modelo proposto estava inadequado do ponto de vista estrutural, já que o coeficiente estrutural do constructo comportamento que o conecta ao constructo qualidade de interação apresentou valor que não atendia rigorosamente ao critério fixado para o nível de significância $(0,05)$, conforme o Quadro 5. Mesmo assim, optou-se por admitir que a hipótese de coeficiente estrutural igual a zero não foi rejeitada, o que implicou a exclusão da variável latente comportamento do modelo. Logo, uma nova modelagem foi testada (empregaram-se todas as variáveis da modelagem anterior, exceto a variável latente comportamento e as variáveis mensuráveis que funcionavam como seus indicadores).

Quadro 5 - Valores de t para os coeficientes estruturais

\begin{tabular}{|c|c|c|}
\hline Coeficiente estrutural & t & Sig. \\
\hline Qualidade de interação x Qualidade de serviço & 3,372 & 0,001 \\
\hline Qualidade do resultado x Qualidade de serviço & 3,067 & 0,002 \\
\hline Aspectos tangíveis x Qualidade do resultado & 5,507 & 0,000 \\
\hline Tempo de espera x Qualidade do resultado & 2,144 & 0,032 \\
\hline Expertise x Qualidade de interação & 5,089 & 0,000 \\
\hline Comportamento x Qualidade de interação & 1,948 & 0,051 \\
\hline Atitude x Qualidade de interação & 2,003 & 0,046 \\
\hline
\end{tabular}

Fonte: elaborado pelos autores.

Essa última modelagem se ajustou muito bem aos dados: a avaliação do modelo de mensuração revelou que as relações entre os indicadores e as variáveis latentes (constructos) são suficientemente robustas, enquanto a avaliação do modelo estrutural apontou elevados indicadores de ajuste geral (Quadro 6).

Quadro 6 - Avaliação do modelo estrutural

\begin{tabular}{|c|l|}
\hline $\begin{array}{c}\text { Estimativas para os valores } \\
\text { dos coeficientes estruturais }\end{array}$ & $\begin{array}{l}\text { Todos os coeficientes estruturais são diferentes de zero (com nível } \\
\text { de significância estatística inferior a 0,05). }\end{array}$ \\
\hline $\mathrm{R}^{2}$ & $\begin{array}{l}\mathrm{R}^{2} \text { de Qualidade de Serviço }=0,740 \text { (substancial) } \\
\mathrm{R}^{2} \text { de Qualidade de Interação }=0,788 \text { (substancial) } \\
\mathrm{R}^{2} \text { de Qualidade de Resultado }=0,660 \text { (substancial) }\end{array}$ \\
\hline Goodness-of-fit (GoF) & GoF $=0,757854$ (Valor superior ao considerado mínimo aceitável) \\
\hline
\end{tabular}

Fonte: elaborado pelos autores.

A Figura 4, exposta a seguir, mostra a modelagem em sua forma final e explicita os valores dos coeficientes estruturais obtidos. 
Figura 4 - Modelo válido para o serviço Layout

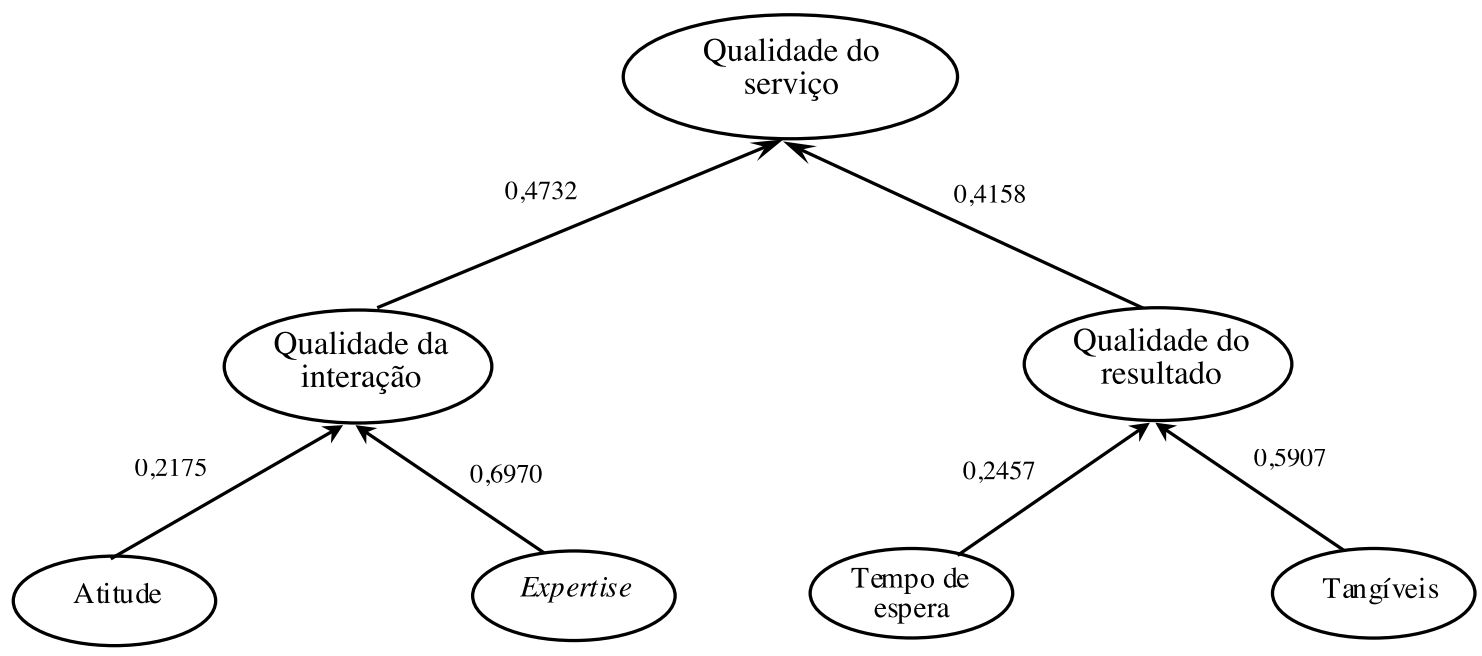

Uma vez revelado o modelo adequado para o serviço em questão, foi possível enfim dimensionar a importância de cada elemento conceitual para a composição da qualidade do serviço. O Quadro 7 apresenta as hipóteses confirmadas pelo modelo e as variáveis empregadas em sua composição.

Quadro 7 - Hipóteses confirmadas e variáveis

\begin{tabular}{|c|l|l|}
\hline \multicolumn{1}{|c|}{ Hipótese } & \multicolumn{1}{|c|}{ Variáveis } \\
\hline $\mathrm{H}_{1}$ & $\begin{array}{l}\text { A percepção sobre a qualidade de interação contribui } \\
\text { diretamente para a percepção da qualidade do servi- } \\
\text { ço. }\end{array}$ & $\begin{array}{l}\text { Qualidade da interação (V45 a V47) e Qua- } \\
\text { lidade do serviço (V51 a V53). }\end{array}$ \\
\hline $\mathrm{H}_{2}$ & $\begin{array}{l}\text { A percepção sobre as atitudes dos funcionários das } \\
\text { empresas terceirizadas influencia diretamente a per- } \\
\text { cepção da qualidade de interação. }\end{array}$ & $\begin{array}{l}\text { Atitude (V17 a V25) e Qualidade da intera- } \\
\text { ção (V45 a V47). }\end{array}$ \\
\hline $\mathrm{H}_{4}$ & $\begin{array}{l}\text { A percepção sobre a expertise dos funcionários das } \\
\text { empresas terceirizadas influencia diretamente a per- } \\
\text { cepção da qualidade de interação. }\end{array}$ & $\begin{array}{l}\text { Expertise (V36 a V44) e Qualidade da inte- } \\
\text { ração (V45 a V47). }\end{array}$ \\
\hline $\mathrm{H}_{5}$ & $\begin{array}{l}\text { A percepção sobre a qualidade do resultado contribui } \\
\text { diretamente para a percepção da qualidade do servi- } \\
\text { ço. }\end{array}$ & $\begin{array}{l}\text { Qualidade do resultado (V48 a V50) e Qua- } \\
\text { lidade do serviço (V51 a V53). }\end{array}$ \\
\hline $\mathrm{H}_{6}$ & $\begin{array}{l}\text { A percepção sobre o tempo de espera influencia dire- } \\
\text { tamente a percepção da qualidade do resultado. }\end{array}$ & $\begin{array}{l}\text { Tempo de espera (V10 a V16) e Qualidade } \\
\text { do resultado (V48 a V50). }\end{array}$ \\
\hline $\mathrm{H}_{7}$ & $\begin{array}{l}\text { A percepção sobre os aspectos tangíveis do serviço } \\
\text { influencia diretamente a percepção da qualidade do } \\
\text { resultado. }\end{array}$ & $\begin{array}{l}\text { Aspectos tangíveis (V1 a V9) e Qualidade } \\
\text { do resultado (V48 a V50). }\end{array}$ \\
\hline
\end{tabular}

Fonte: elaborado pelos autores.

O Quadro 8 e o Quadro 9, transcritos a seguir, apresentam as contribuições de cada constructo para a explicação das variâncias dos constructos endógenos (qualidade de interação, qualidade do resultado e qualidade do serviço), as quais foram calculadas com base na exposição de Bido et al. (2008), isto é, como produto do valor do coeficiente estrutural que liga os dois constructos com o valor da correlação entre esses constructos. 
Quadro 8 - Contribuição de cada constructo para explicação da variância da qualidade do serviço

\begin{tabular}{|c|c|c|c|}
\hline Constructos & $\begin{array}{c}\text { Coeficiente estrutural do } \\
\text { constructo com Qualidade } \\
\text { do serviço }\end{array}$ & $\begin{array}{c}\text { Correlação do constructo } \\
\text { com Qualidade do serviço }\end{array}$ & $\begin{array}{c}\text { Contribuição para a variação } \\
\text { da Qualidade do serviço }\end{array}$ \\
\hline $\begin{array}{c}\text { Qualidade de } \\
\text { interação }\end{array}$ & 0,4732 & 0,8354 & 0,3953 \\
\hline $\begin{array}{c}\text { Qualidade do } \\
\text { resultado }\end{array}$ & 0,4158 & 0,828 & 0,3443 \\
\hline & \multicolumn{2}{|c|}{$R^{2}$ Qualidade do serviço $=0,740$} & Soma $=0,7396$ \\
\hline
\end{tabular}

Fonte: elaborado pelos autores.

O constructo qualidade de interação desempenha o papel principal para a definição da qualidade do serviço de layout, pois explica $39,53 \%$ da variância da qualidade do serviço $(0,3953$ $x$ 100), enquanto o constructo qualidade do resultado explica $34,43 \%(0,3443 \times 100)$. Talvez a explicação para isso seja o fato de que boa parte da prestação desse serviço está bastante associada a uma fase de projeto, na qual geralmente é preciso contar com a participação dos usuários.

Quadro 9 - Contribuição de cada constructo para explicação da variância dos constructos endógenos

\begin{tabular}{|c|c|c|c|}
\hline Constructos & $\begin{array}{c}\text { Coeficiente estrutural do } \\
\text { constructo com Qualidade } \\
\text { do resultado }\end{array}$ & $\begin{array}{c}\text { Correlação do cons- } \\
\text { tructo com Qualidade } \\
\text { do resultado }\end{array}$ & $\begin{array}{c}\text { Contribuição para a variação } \\
\text { da Qualidade do resultado }\end{array}$ \\
\hline Aspectos tangíveis & 0,5907 & 0,8028 & 0,4742 \\
\hline Tempo de espera & 0,2457 & 0,7556 & 0,1856 \\
\hline & $R^{2}$ Qualidade do resultado= 0,660 & Soma $=0,6598$ \\
\hline & $\begin{array}{c}\text { Coeficiente estrutural do } \\
\text { constructo com Qualidade } \\
\text { de interação }\end{array}$ & $\begin{array}{c}\text { Correlação do cons- } \\
\text { tructo com Qualidade } \\
\text { de interação }\end{array}$ & $\begin{array}{c}\text { Contribuição para a variação } \\
\text { da Qualidade de interação }\end{array}$ \\
\hline Atitude & 0,2175 & 0,8026 & 0,1746 \\
\hline Expertise & 0,6970 & 0,8796 & 0,6131 \\
\hline & \multicolumn{2}{|c|}{$\mathrm{R}^{2}$ Qualidade da interação $=0,788$} & Soma $=0,7877$ \\
\hline
\end{tabular}

Fonte: elaborado pelos autores.

Quanto à contribuição dos constructos exógenos aspectos tangíveis e tempo de espera para a variação do constructo qualidade do resultado (Quadro 9), cabe ressaltar a expressiva vantagem numérica do valor da contribuição do constructo aspectos tangíveis em relação ao constructo tempo de espera $(0,4742$ versus 0,1856$)$. Já no que se refere à contribuição dos constructos exógenos atitude e expertise para a variação do constructo qualidade de interação (Quadro 9), nota-se que a maior importância é do constructo expertise $(0,6131$ versus 0,1746$)$.

\subsection{Comparação entre as três categorias de respondentes}

Os resultados da modelagem em equações estruturais viabilizaram a hierarquização dos constructos em termos de importância relativa (Quadro 10).

Quadro 10 - Importância relativa dos constructos

\begin{tabular}{|c|c|c|}
\hline Constructos & Contribuição para a variação da Qualidade do serviço & $\begin{array}{c}\text { Importância } \\
\text { relativa }\end{array}$ \\
\hline Qualidade de interação & 0,3953 & 1 \\
\hline Qualidade do resultado & 0,3443 & 2 \\
\hline & Contribuição para a variação da Qualidade do resultado & \\
\hline
\end{tabular}




\begin{tabular}{|c|c|c|}
\hline Aspectos tangíveis & 0,4742 & 1 \\
\hline Tempo de espera & 0,1856 & 2 \\
\hline & Contribuição para a variação da Qualidade de interação & \\
\hline Atitude & 0,1746 & 2 \\
\hline Expertise & 0,6131 & 1 \\
\hline
\end{tabular}

Fonte: elaborado pelos autores.

A partir dessa hierarquização, foi possível fazer uma comparação com as hierarquizações feitas pelas outras duas categorias de respondentes na etapa de realização da pesquisa qualitativa. A Figura 5 permite a visualização conjunta das respostas das três categorias de respondentes, de modo a favorecer a comparação sobre a importância relativa dada a cada constructo.

Urge destacar que houve discordância entre a importância dos constructos qualidade de interação e qualidade do resultado entre usuários e as outras duas categorias de respondentes (fiscais de contratos e responsáveis pelos prestadores de serviços): enquanto os usuários consideram qualidade de interação como mais importante, os fiscais de contratos e os responsáveis pelos prestadores de serviços consideram qualidade do resultado como mais importante. Isso pode traduzir uma lacuna de percepção por parte desses agentes em relação ao aspecto de maior importância na prestação desse tipo de serviço, especialmente no que se refere a projetos de alteração da disposição de mobiliário e de divisórias.

Contudo, quanto à importância dos constructos exógenos aspectos tangíveis e tempo de espera, houve convergência entre usuários e fiscais de contratos, o que pode indicar uma boa percepção destes em relação aos aspectos valorizados por seus clientes, em contraste com a indefinição dos responsáveis pelos prestadores do serviço. Essa convergência se repete em relação aos constructos exógenos atitude e expertise, o que reforça a hipótese referente à boa percepção dos fiscais de contratos sobre o que os usuários valorizam nesse serviço, o que mais uma vez contrasta com a percepção dos responsáveis pela prestação do serviço (apontaram a atitude como mais importante que a expertise).

Figura 5 - Hierarquização da importância relativa dos constructos para cada categoria de respondentes.

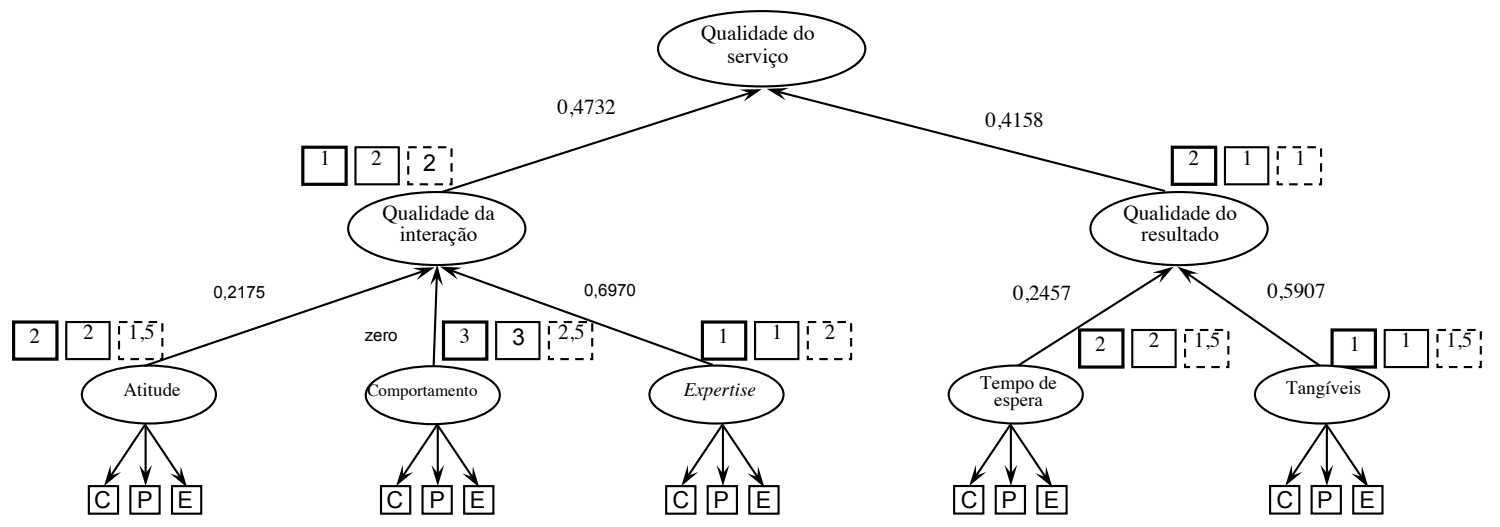

Nota: $\mathrm{C}=$ item de confiabilidade; $\mathrm{P}=$ item de prontidão e $\mathrm{E}=$ item de empatia. $\quad$ Os valores em negrito indicam as medianas das respostas

Respostas dos usuários
valores obtidos a partir da

ordenação dos valores dos

coeficientes estruturais

Respostas dos fiscais de
contratos
ordenação dos constructos




\subsection{Avaliação dos indicadores}

Além da investigação acerca da importância dos constructos, cabe conhecer a avaliação de cada indicador por categoria de respondentes, a fim de examinar se há ou não alguma diferença na forma de julgar a qualidade desse serviço em função do papel desempenhado pelo respondente (usuário, fiscal de contrato ou responsável pelos prestadores de serviços). Foi realizado, para cada indicador, o teste não paramétrico de igualdade de médias de Kruskal-Wallis, recomendado quando se comparam as médias de três grupos de respondentes.

Uma análise conjunta dos resultados permite concluir que, no geral, não há diferença entre a avaliação feita para esse serviço por usuários, fiscais de contrato e responsáveis pelos prestadores de serviços, embora, em alguns poucos indicadores, os responsáveis pelos prestadores do serviço tendessem a indicar maiores notas para o serviço prestado do que os usuários. Nota-se, também, uma tendência de os usuários considerarem o serviço como bom, enquanto a tendência entre os fiscais de contratos e os responsáveis pelos prestadores do serviço é de considerá-lo ótimo. Apenas no caso de um indicador (proatividade - V20) houve uma divergência entre essas duas últimas categorias de respondentes, com média bem maior atribuída pelos responsáveis pelos prestadores de serviços.

Um exame dos valores das médias atribuídas às variáveis permite concluir que, de modo geral, esse é considerado um ótimo serviço, já que a média da grande maioria das variáveis se situa dentro do intervalo de valores que traduzem o conceito de ótima avaliação (valores de 7,5 a $10,0)$. Além disso, uma considerável quantidade de variáveis recebeu avaliação classificada como boa (valores de 5,0 a 7,4), e nenhuma variável foi apontada como indicador de serviço ruim ou péssimo, o que reforça mais ainda tal conclusão.

\section{CONCLUSÕES}

Este estudo foi realizado com o propósito de identificar, no âmbito de uma organização pública autárquica, indicadores que possibilitassem uma avaliação da qualidade do serviço terceirizado de manutenção em um pacote de serviços denominado layout, abarcando reparos em móveis e alterações das posições do mobiliário e das divisórias, considerando-se as perspectivas dos usuários, dos fiscais de contratos e dos responsáveis pelos prestadores de serviços.

A empresa selecionada para este estudo apresentava a situação de ter esses serviços avaliados somente por fiscais pertencentes ao seu quadro de funcionários e outros servidores responsáveis pelo acompanhamento dos serviços contratados. Consequentemente, não se sabia se os serviços terceirizados contratados eram considerados de qualidade também pelos usuários (funcionários da empresa) e pelos prestadores dos serviços. Porém, informalmente, havia algumas reclamações esporádicas dos usuários, o que motivou a realização de uma pesquisa com este segmento e com os demais agentes envolvidos: fiscais e prestadores dos serviços.

À luz de uma adaptação do modelo de Brady e Cronin Jr. (2001), foram identificados alguns constructos que poderiam conduzir à avaliação da qualidade percebida na prestação dos serviços de manutenção de layout. Além da fonte teórica, julgou-se pertinente a realização de pesquisas qualitativas junto aos usuários, fiscais e prestadores de serviços para a definição dos indicadores componentes de cada constructo. Posteriormente, realizou-se uma pesquisa quantitativa com os usuários, solicitando a sua avaliação para cada indicador inerente aos constructos do modelo do estudo.

Por meio da técnica estatística de modelagem de equações estruturais, chegou-se à definição dos constructos diretamente relevantes para a aferição da qualidade do serviço de manu- 
tenção de layout (qualidade da interação e qualidade do resultado), bem como à identificação dos constructos primários que os influenciam: atitude, expertise (qualidade da interação), tempo de espera e aspectos tangíveis (qualidade do resultado). Com a hierarquização de importância de cada um dos constructos para os respectivos constructos dependentes, proporcionada pelas estatísticas da modelagem de equações estruturais, foi possível analisar a importância dada pelos usuários aos fatores que influenciam a qualidade percebida desses serviços.

Com base nos resultados das pesquisas qualitativas, foram obtidos os rankings dos constructos pela ótica dos fiscais e dos prestadores de serviços. Assim, foi possível comparar os rankings dos aspectos que conduzem à qualidade percebida dos serviços segundo os três segmentos de interesse neste trabalho. Finalmente, fizeram-se testes de igualdade de médias das notas atribuídas pelos três grupos para os indicadores inerentes aos constructos do modelo de estudo.

Dentro das limitações inerentes à opção metodológica adotada, alcançou-se o objetivo proposto, uma vez que foram obtidas respostas para as questões colocadas. A primeira delas, referente à identificação dos aspectos relevantes na avaliação da qualidade do serviço de layout, obteve resposta na medida em que o trabalho arrolou os aspectos que influenciam a qualidade percebida dos serviços de layout, segundo os três estratos de interesse (usuários, fiscais e prestadores de serviços): a partir dos Quadros 1, 2 e 3, podem ser identificados 41 indicadores (denominados como variáveis no estudo) úteis para a avaliação da qualidade do serviço de layout, considerando-se a exclusão de 12 variáveis (V20, V26, V27, V28, V29, V30, V31, V32, V33, V34, V35 e V50). Cabe salientar que a exclusão dessas variáveis, motivada pela avaliação do modelo de mensuração e do modelo estrutural no processamento dos dados referentes aos usuários, faz sentido: via de regra, para os usuários, é muito difícil avaliar indicadores como proatividade (V20), resultados em relação à expectativa (V50) ou quaisquer das variáveis que compõem o constructo comportamento (V26 a V35), uma vez que se referem a aspectos mais perceptíveis apenas para quem acompanha de perto a execução do serviço - aliás, esses indicadores foram sugeridos por fiscais e prestadores de serviços na fase da pesquisa qualitativa.

Consequentemente, a implicação prática imediata, no âmbito da organização pública pesquisada, é que os 41 indicadores validados poderão servir para operacionalizar a avaliação periódica da qualidade do serviço de layout, mediante emprego de instrumentos de coleta de dados criados com base nos resultados desta pesquisa.

Em termos de contribuição teórica para o aprimoramento do conhecimento no tema avaliação da qualidade de serviços, destaca-se a confirmação da validade do encadeamento dos constructos qualidade do serviço, qualidade do resultado e qualidade de interação, propostos no Modelo de Brady e Cronin Jr. (2001): a partir dos dados obtidos dos usuários, verificou-se que o constructo qualidade do serviço é definido pelos constructos qualidade do resultado (responsável por $34,43 \%$ da variância da qualidade do serviço) e qualidade de interação (que explica 39,53\% da variância da qualidade do serviço). Também foi confirmada a validade do encadeamento dos constructos qualidade do resultado com os constructos tempo de espera e aspectos tangíveis, bem como do constructo qualidade de interação com os constructos expertise e atitude - vide as hipóteses confirmadas (Quadro 7).

Outro resultado que merece destaque é a verificação da importância relativa de cada constructo de mesmo nível (Figura 5): foi verificada discordância de opinião no que se refere à maior importância relativa do constructo qualidade do resultado (mais importante para os fiscais e prestadores de serviços) em relação ao constructo qualidade de interação (mais importante para os usuários); no que se refere aos demais constructos, houve convergência apenas entre as indicações dos usuários e dos fiscais de contratos - nenhuma das opiniões dos responsáveis pe- 
los prestadores de serviços sobre a importância relativa desses constructos coincidiu com a dos usuários e fiscais de contratos. Tal resultado pode sugerir que os fiscais de contrato, de um modo geral, conseguem captar satisfatoriamente as expectativas dos usuários e que pode haver alguma dificuldade dos responsáveis pelos prestadores de serviços em identificar os elementos mais relevantes para a execução do serviço na visão dos usuários e dos fiscais de contratos. Além disso, a existência de algumas diferenças de opinião entre os três segmentos realça a complexidade de avaliação de serviços no contexto de layout.

Já o grau de qualidade percebida do serviço de layout foi mensurado a partir da apuração das notas atribuídas pelos respondentes: o estudo revelou que o serviço foi considerado predominantemente bom pelos usuários e ótimo pelos fiscais e prestadores de serviços. Cabe notar que, de modo geral, não foi detectada diferença significativa na avaliação de usuários, fiscais de contratos e responsáveis pelos prestadores de serviços quanto às notas atribuídas para a qualidade do serviço (os testes de igualdade de médias feitos para cada indicador revelaram que apenas para um dos 53 indicadores avaliados houve diferença significativa entre as notas atribuídas). Ademais, a média da nota atribuída para a grande maioria das variáveis situa-se dentro do intervalo de valores que traduzem o conceito de ótima avaliação (valores de 7,5 a 10,0). Portanto, pode-se supor que a atuação dos fiscais de contratos na cobrança de resultados da empresa prestadora de serviço tem sido satisfatória, bem como que a atuação dos responsáveis pelos prestadores de serviços tem sido suficientemente aceitável.

Uma vez que se trata de um estudo exploratório desenvolvido para uma organização pública específica, cabe ressaltar que uma generalização da validade do modelo teórico empregado (adaptado do Modelo de Brady e Cronin Jr.) só poderá ser obtida após replicações deste estudo, preferencialmente avaliando-se o mesmo tipo de serviço. Isso representa uma potencial fonte para pesquisas futuras. Outra possibilidade seria a replicação do estudo empregando outros serviços terceirizados de manutenção predial, a fim de verificar se o modelo adaptado é capaz de permitir uma boa avaliação da qualidade desses serviços.

A principal limitação deste estudo consiste, assim, em não ser possível generalizar os resultados, mas apenas obter um indício de que os 41 indicadores identificados podem permitir a avaliação da qualidade do serviço terceirizado, aqui identificado como serviço de layout. Este trabalho proporcionou, contudo, o levantamento dos aspectos que influenciam a qualidade percebida dos serviços de manutenção de layout segundo três estratos de interesse (usuários, fiscais e prestadores de serviços), de modo que os indicadores obtidos poderão ser levados em conta na elaboração dos contratos entre fornecedores e contratante e atuar como referências no monitoramento da prestação de manutenção de layout. 


\section{REFERÊNCIAS}

ANGUR, Madhukar G. et al. Service quality in the banking industry : an assessment in a developing economy. International Journal of Bank Marketing. Bradford: MCB University Press, v. 17, n. 3, p. 116-125, 1999.

BAYRAKTAROGLU, Gul. Testing the Superiority and Dimensionality of Servqual Vs. Servperf in Higher Education. Quality Management Journal. v. 17, n. 1, Jan. 2010, p. 47-59.

BIDO, Diógenes de S. et al. Examinando a relação entre aprendizagem individual, grupal eorganizacional em uma instituição financeira. In: XXXII ENANPAD - Encontro Nacional dos Programas de Pós-Graduação em Administração, Rio de Janeiro, 2008. Anais... Rio de Janeiro: Anpad, 2008.

BRADY, Michael K; CRONIN JR, Joseph J. Some new thoughts on conceptualizing perceived service quality: a hierarchical approach. Journal of Marketing. Chicago, v. 65, n. 3, p.3449, july 2001.

Brasil. Lei 8.666 de 21/06/1993. Diário Oficial da União: Poder Executivo. Brasília, 22/06/1993.

Brasil. Lei 10.520 de 17/07/2002. Diário Oficial da União: Poder Executivo. Brasília, 18/07/2002.

BUCHNER, Axel; ERDFELDER, Edgard; FAUL, Franz; LAG, Albert-George. G*Power version 3.0.10. Kiel, 2008. Disponível em: < http:// www.psycho.uni-duesseldorf.de/aap/ projects/gpower/ >. Acesso em: 28.11.08.

CALADO, Silvia dos Santos; FERREIRA, Silvia Cristina dos Reis. Análise de documentos: método de recolha e análise de dados. Trabalho de Conclusão de Curso (Metodologia de Investigação I) - Departamento de Educação da Faculdade de Ciências. Lisboa: Universidade de Lisboa, 2005. Disponível em: < http:// www.educ.fc.ul.pt/docentes/ichagas/mi1/ analisedocumentos.pdf $>$. Acesso em: 11.02.08.

CARMAN, J. M. Consumer perceptions of service quality: an assessment of the SERVQUAL Dimensions. Journal of Retailing. New York: New York University, v. 66, n. 1, p. 33-55, 1990.

CARO, Laura Martínez; GARCÍA, Jose Antonio Martínez. Developing a multidimensional and hierarchical service quality model for the travel agency industry. Tourism Management. v. 29, n. 4 , Aug. 2008, p. 706-720.

CARVALHO, Frederico A.; LEITE, Valdecy F. Refinando a conjetura PBZ: uma revisão da relação entre importância e tolerância em qualidade de serviços. Revista de Administração Contemporânea. Rio de Janeiro, v. 5, n. 1, p. 43-60, 2001.

CHAHAL, Hardeep; KUMARI, Neetu. Development of multidimensional scale for healthcare service quality (HCSQ) in Indian context. Journal of Indian Business Research. v. 2, n. 4, 2010, p. $230-255$.

CRONIN JR., J. J.; TAYLOR, S. A. Measuring service quality: a reexamination and extension. Journal of Marketing. Chicago, v. 56, n. 2, p. 5568, July 1992.

CRONIN JR., J. Joseph; TAYLOR, Steven A. SERVPERF versus SERVQUAL: reconciling performance-based and perceptions-minusexpectations measurement of service quality. Journal of Marketing. Chicago, v. 58, p. 125131, 1994.

CUI, Charles Chi et al. Service quality measurement in the banking sector in South Korea. International Journal of Bank Marketing. Bradford, v. 21, n. 4, p. 191-201, 2003.

DABHOLKAR, P.; THORPE, D. I.; RENTZ, J. Q. A measure of service quality for retail stores. Journal of the Academy of Marketing Science. Greenvale, v. 24, n. 1, p. 3-16, Winter 1996. 
FASSNACHT, M.; COESE, I. Quality of electronic services: conceptualizing and testing a hierarchical model. Journal of Service Research, v. 9, n. 1, p. 19-37, 2006.

GONÇALVES, Carlos A. et al. Avaliação de um modelo de mensuração de desempenhol de serviços oferecidos por empresas públicas. In: VII Congresso Internacional del Clad, 2002. Anais... Lisboa, 2002.

GRÖNROOS, Christian. Marketing: gerenciamento e serviços: a competição por serviços na hora da verdade. Rio de Janeiro: Campus, 1993.

HAIR JR., Joseph F. et al. Análise multivariada da dados. Porto Alegre: Bookman, 2005.

JAIN, Sanjay K; GUPTA, Garima. Measuring Service Quality: SERVQUAL vs. SERVPERF Scales. Vikalpa. v.29, n.02, abr./jun. 2004, p. 25-37.

JENSEN, Anker; VOORDT, Theo van der; COENEN, Christian; VON FELTEN, Daniel; LINDHOLM, Anna-Liisa; NIELSEN, Susanne Balslev; RIRATANAPHONG, Chaiwat; SCHMID, Mirjam. The Added Value of FM: Different Research Perspectives. In: 9th Euro Facility Management Research Symposium. Madrid, 2010.

LASSAR, Walfried M. et al. Service quality perspectives and satisfaction in private banking. Journal of Services Marketing. Bradford, v. 14, n. 3, p. 244-271, 2000.

LAVILLE, Christian; DIONNE, Jean. A construção do saber: manual de metodologia da pesquisa em Ciências Humanas. Porto Alegre: Editora Artes Médicas Sul; Belo Horizonte: Editora UFMG, 1999.

LEE, Haksik et al. The determinants of perceived service quality and its relationship with satisfaction. Journal of Service Marketing. Bradford, v. 14, n. 3, p. 217-231, 2000.

LU, Yaobin; ZHANG, Long; WANG, Bin. A multidimensional and hierarchical model of mobile service quality. Electronic Commerce Research and Applications. v. 8, n. 5, Oct. 2009, p. 228-240.

MARCOLIDES, George A; CHIN, Wynne W; SAUNDERS, Carol. A critical look at Partial Least Squares Modeling. MIS Quarterly. v. 33, n.1, march 2009, p.171-175.

MATOS, C. A.; VEIGA, R. T. Avaliação da qualidade percebida de serviços: um estudo em uma organização não-governamental. Caderno de Pesquisas em Administração. São Paulo, v. 7, n. 3, jul./set., 2000.

MEHTA, Subhash C.; DURVASULA, Srinivas. Relationships between SERVQUAL dimensions and organizational performance in the case of a business-to-business service. Journal of Business \& Industrial Marketing. Bradford, v. 13, n. 1, p. 40-53, 1998.

MELLO, S.C.B. et al. Aplicação do modelo SERVQUAL para a avaliação da qualidade de serviço numa instituição de ensino superior baseado na percepção dos alunos. In: XXII Encontro Nacional de Engenharia de Produção. Anais...Curitiba, 2002.

MIGUEL, Paulo Augusto Cauchik; SALOMI, Gilberto Eid. Uma revisão dos modelos para medição da qualidade em serviços. Revista Produção. São Paulo, v. 14, n. 1, p. 12-30, 2004.

MITTAL, Sanjiv; GERA, Rajat; SINGHVI, S. R. Customer perceived service quality for life insurance services. Asia-Pacific Journal of Management Research and Innovation, v. 9, n. 1, p.63-76, 2013.

MORSE, Janice M. Designing funded qualitative research. In: DENZIN, Norman K; LINCOLN, Yvonna S. Handbook of qualitative research. Tousand Oaks: Sage Publications, 1994.

OLIVER, Richard L. A cognitive model of the antecedents and consequences of satisfaction decisions. Journal of Marketing Research. Chicago, v. 17, p. 460-469, 1980. 
PARASURAMAN, A; ZEITHAML, Valerie A; BERRY, Leonard L. A conceptual model of service quality and its implications for future research. Journal of Marketing. v. 49, n. 4, p. 41-50, 1985.

PARASURAMAN, A; ZEITHAML, Valerie A; BERRY, Leonard L. SERVQUAL: a multiple-item scale for measuring consumer perceptions of service quality. In: Journal of Retailing. v.64, n.1, spring 1988, p.12-40.

PARASURAMAN, A. et al. Alternative scales for measuring service quality: a comparative assessment based on psychometric and diagnostic criteria. Journal of Retailing. New York: New York University Press, v. 70, n. 3, p. 201-230, 1994.

PEREIRA, Luiz C. B. Do Estado patrimonial ao gerencial. In: PINHEIRO, Wilheim, J. e Sachs I. (Orgs.). Brasil: um século de transformações. São Paulo: Cia. das Letras, 2001.

REIS, Izabel Cristina da Silva. A escala SERVQUAL modificada: avaliação da qualidade percebida do serviço de lazer oferecido por um complexo poliesportivo num parque florestal. Florianópolis, 2001. Dissertação (Mestrado em Engenhara de Produção) - Programa de Pós-Graduação em Engenharia de Produção, Universidade Federal de Santa Catarina.

RUST, R. T.; OLIVER, R. L. Service Quality: new directions in theory and practice. Thousand Oaks, California: SAGE Publication, 1994.

SALOMI, Gilberto Gabriel Eid et al. SERVQUAL x SERVPERF: comparação entre instrumentos para avaliação da qualidade de serviços internos. Gestão e Produção. São Carlos, v. 12, n. 2, 2005.

SIMIÉ, M. L.; CARAPIÉ, H. Education service quality of a business school: former and current students' evaluation. International Review on Public and Nonprofit Marketing, v. 5, p. 181-191, 2008.

SURESHCHANDAR, G. S. et al. Determinants of customer-perceived service quality: a confirmatory factor analysis approach. Journal of Services Marketing. Bradford, v. 16, n. 1, p. 9-34, 2002.

TEAS, R. Kenneth. Expectation, performance evaluation and costumer's perception of quality. Journal of Marketing. Chicago, v. 57, n. 4, p. 18-34, 1993.

TEAS, R. Kenneth. Expectations as a comparison standard in measuring service quality: an assessment of a reassessment. Journal of Marketing. Chicago, v. 58, p. 132-139, 1994.

VÖLCKNER, Franziska; SATTLER, Henrik; HENNIG-THURAU, Thorsten; RINGLE, Christian $M$. The role of parent brand quality for service brand extension success. Journal of Service Research, v.13, n. 4, p.379-396, 2010.

YIN, R.K. Estudo de caso: planejamento e métodos. Porto Alegre: Bookman, 2005.

YOON, S.; SUH, H. Ensuring IT consulting SERVQUAL and user satisfaction: a modified measurement tool. Information Systems Frontiers, v. 6, n. 4, p. 341-351, 2004.

ZEITHAML, Valarie A. et al. Delivering quality service: balancing customer perceptions and expectations. New York: The Free Press, 1990.

ZWICKER, R.; SOUZA, C. A.; BIDO, D. S. Uma revisão do modelo do grau de informatização de empresas: novas propostas de estimação e modelagem usando PLS (partial least squares). In: XXXII ENANPAD - Encontro Nacional dos Programas de Pós-Graduação em Administração, Rio de Janeiro, 2008. Anais... Rio de Janeiro: Anpad, 2008. 